University of Wollongong

Research Online

Faculty of Engineering and Information

Faculty of Engineering and Information

Sciences - Papers: Part A

Sciences

$1-1-2013$

\title{
A mathematical function to represent S-shaped relationships for geotechnical applications
}

Martin D. Liu

University of Wollongong, martindl@uow.edu.au

$\mathrm{K} \mathrm{J} . \mathrm{Xu}$

Pb Americas, Incorporated

Suksun Horpibulsuk

Suranaree University of Technology, suksun@g.sut.ac.th

Follow this and additional works at: https://ro.uow.edu.au/eispapers

Part of the Engineering Commons, and the Science and Technology Studies Commons

Research Online is the open access institutional repository for the University of Wollongong. For further information contact the UOW Library: research-pubs@uow.edu.au 


\title{
A mathematical function to represent S-shaped relationships for geotechnical applications
}

\author{
Abstract \\ In this paper a new mathematical function is proposed for describing the S-shape relationship in both \\ normal $x$ and $y$ scale and the semi-logarithmic $x$ and $y$ scale. Basic features of the proposed function have \\ been demonstrated. The proposed function has then been used to simulate the S-shape relationship for \\ seven categories of engineering phenomena. It is seen that the proposed mathematical function has a \\ great potential for representing various S-shape relationships and provides a powerful tool for \\ characterising properties of materials or response of systems; it is thus useful for further numerical \\ analysis.

\section{Keywords} \\ relationships, shaped, represent, applications, function, geotechnical, mathematical

\section{Disciplines} \\ Engineering | Science and Technology Studies

\section{Publication Details} \\ Liu, M. D., Xu, K. J. \& Horpibulsuk, S. (2013). A mathematical function to represent S-shaped relationships \\ for geotechnical applications. Institution of Civil Engineers. Proceedings. Geotechnical Engineering, 166 \\ (GE3), 321-327.
}


Geotechnical Engineering

Volume 166 Issue GE3

A mathematical function to represent S-shaped relationships for geotechnical applications

Liu, Xu and Horpibulsuk
Proceedings of the Institution of Civil Engineers Geotechnical Engineering 166 June 2013 Issue GE3 Pages 321-327 http://dx.doi.org/10.1680/geng.10.00029 Paper 1000029

\section{A mathematical function to represent S-shaped relationships for geotechnical applications}

1 Martin D. Liu MPhl, PhD Senior Lecturer, University of Wollongong, New South Wales, Australia

2 K. J. Xu PhD

PB Americas, Incorporated, New York, USA
3 Suksun Horpibulsuk MEng, PhD

Professor, Suranaree University of Technology, Nakhon Ratchasima, Thailand
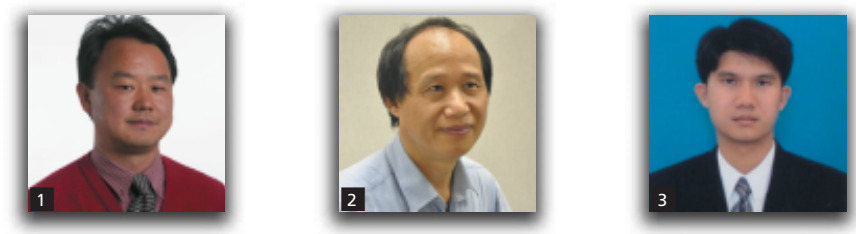

In this paper a new mathematical function is proposed for describing the S-shape relationship in both normal $x$ and $y$ scale and the semi-logarithmic $x$ and $y$ scale. Basic features of the proposed function have been demonstrated. The proposed function has then been used to simulate the S-shape relationship for seven categories of engineering phenomena. It is seen that the proposed mathematical function has a great potential for representing various Sshape relationships and provides a powerful tool for characterising properties of materials or response of systems; it is thus useful for further numerical analysis.

\section{Introduction}

In engineering practice and in physics it has been frequently observed that a characteristic of a material or a response of a system, that is an assembly of a number of objects with finite or infinite sizes, to an external agent may form an S-shaped curve either in normal coordinates or in semi-logarithmic coordinates. For example, the variation of soil strength with the clay fraction has an S-shape relationship in normal coordinates (Figure 1(a), from Lupini et al. (1981)). In the figure, $\varphi_{\mathrm{cs}}$ and $\varphi_{\mathrm{r}}$ represent the critical state friction angle and the residual friction angle, respectively, and $\omega_{\mathrm{c}}$ represents the clay fraction. The compression curves for geomaterials under first loading are S-shaped in the semi-logarithmic scale (Figure 1(b), from Pestana and Whittle (1995)). In the figure $e$ represents the voids ratio, and $\sigma_{\mathrm{v}}^{\prime}$ represents the vertical effective stress. The consolidation deflection of a raft on a deep layer of soil plotted against time is an S-shape relationship (Figure 1(c), from Booker and Small (1984)).

A mathematical description of the characteristics of materials is useful for numerical interpretation of material properties. However, more importantly, a functional expression for the material property is essential for further numerical analysis. The present authors are not aware of such mathematical formulae that give a reliable description of the whole S-shape relationship. Taking the compression behaviour of soil as an example, the compression equation forms a base for most constitutive modelling of soils and some important geotechnical computations (Burland, 1990; Horpibulsuk et al., 2010; Liu and Carter, 2003; Pestana and Whittle, 1995; Suebsuk et al., 2010, 2011). Because there is no efficient way to describe the whole S-shape compression relationship, a common way to describe it is to divide the curve into several segments and then the segment or the segments of interest are modelled by linear relationships (Butterfield and Baligh, 1996; Khalili et al., 2005; Terzaghi and Peck, 1948). In the current paper, a new single mathematical function is proposed for describing the S-shape relationship. The capacities of the S-shape function are demonstrated and evaluated by simulating various Sshape events.

\section{Proposed mathematical function for the S-shape relationship}

\subsection{Proposed equation}

The proposed mathematical function for S-shape relationships is expressed as follows

$$
y= \pm \frac{a_{1}}{x}\left[1+(x-1) \mathrm{e}^{-a_{2} x^{a_{3}}}\right]+b
$$

The first part of the function may take a positive sign in order to simulate the S-shape relationship where $y$ decreases monotonically, and may take a negative sign to simulate the S-shape 


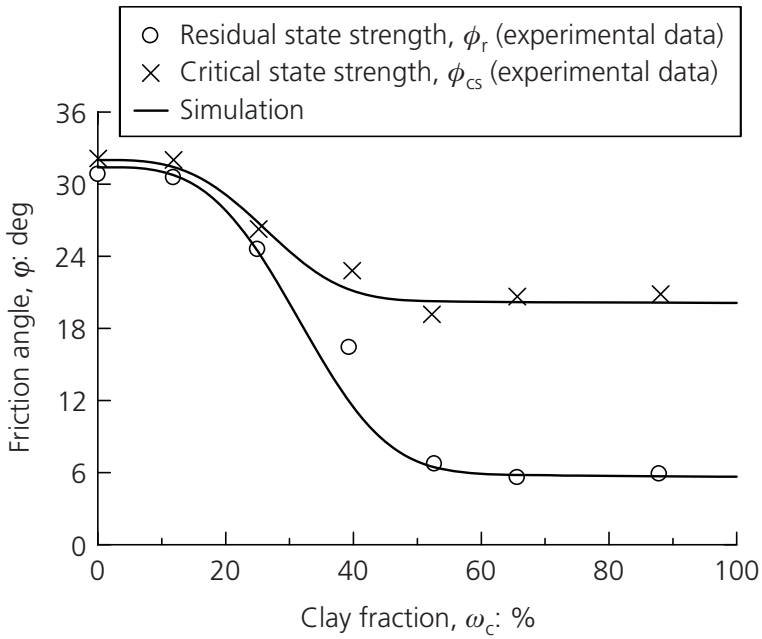

(a)
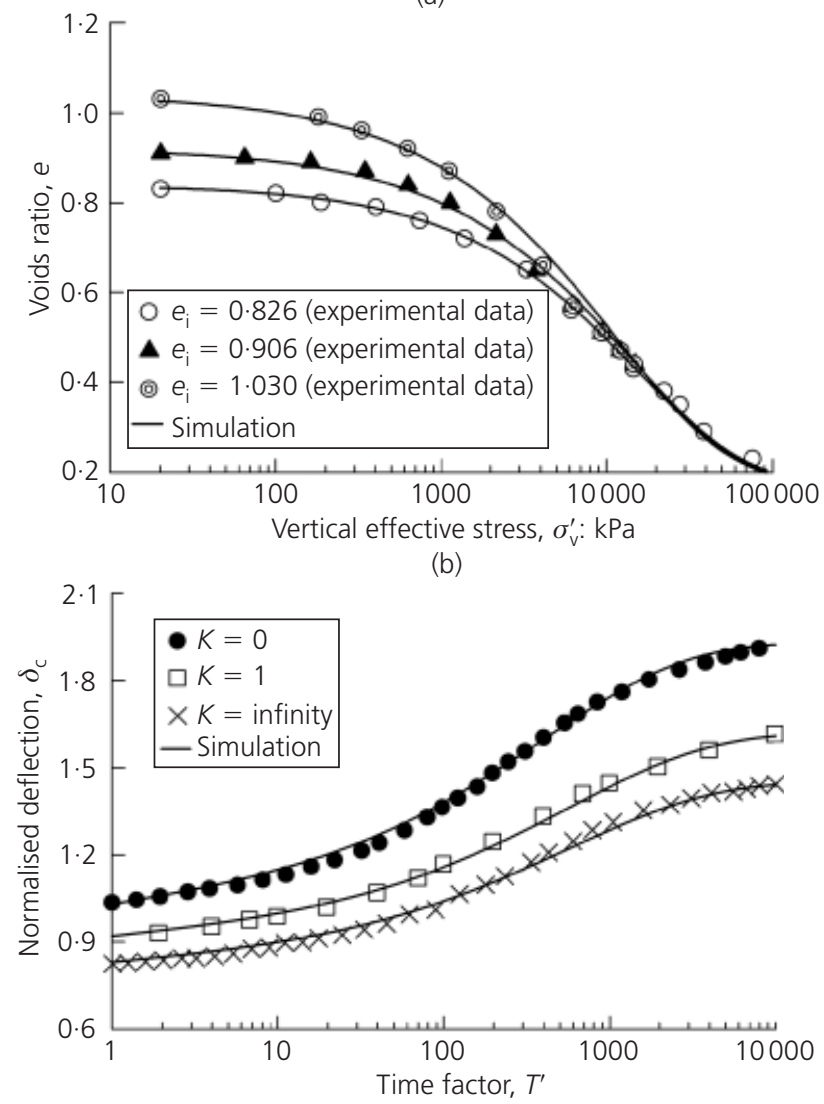

(c)

Figure 1. (a) Variation of the strength of soil with clay fraction (data after Lupini et al. (1981)). (b) One-dimensional compression behaviour of Quiou sand (data after Pestana and Whittle (1995)). (c) Time-deflection of circular raft with flexibility $K$ (theoretical data after Booker and Small (1984))

relationship where $y$ increases monotonically. There are four parameters in the new function: $a_{1}, a_{2}, a_{3}$ and $b$. Parameters $a_{1}$, $a_{2}, a_{3}$ are assumed to be positive. Mathematically, the valid range for variable $x$, which is dependent on $a_{3}$, is given as follows

$$
\text { 2. }\left\{\begin{array}{l}
x \geqslant 0 \text { for } a_{3} \geqslant 1 \\
x>0 \text { for } 0<a_{3}<1
\end{array}\right.
$$

However, for a practical application, the physical meaning of the variable may impose its own valid range on variable $x$.

\subsection{Characteristics of the proposed equation}

Figure 2 shows example curves illustrating the influences of the parameters $a_{1}, a_{2}$ and $a_{3}$ on the S-shape relationship. It can be shown that the proposed function has the following features.

(a) The asymptotic line for the proposed function is $y=b$ and the entire curve remains at one side of the asymptotic line, that is

3. $y \stackrel{x \rightarrow \infty}{\longrightarrow} b$

As seen in Equation 1, the function is rigidly translated along the $y$ axis by the magnitude of $b$. Thus parameter $b$ can be measured from the figure according to the translation of the S-shape relationship along the $y$ axis.

(b) The value of $(y-b)$ varies linearly with the value of parameter $a_{1}$. This is clearly shown in Equation 1 . Therefore, parameter $a_{1}$ is determined by the amplitude of the S-shape curve.

(c) The limit value for $(y-b)$, as $x$ approaches zero, is as follows

4. $(y-b) \stackrel{x \rightarrow 0}{\longrightarrow} \begin{cases}a_{1} & \text { for } a_{3}>1 \\ a_{1}+a_{1} a_{2} & \text { for } a_{3}=1 \\ \infty & \text { for } a_{3}<1\end{cases}$

The function has a singular point at $x=0$ for $a_{3}<1$. The value of $a_{1}$ can be determined from Equation 4 for $a_{3}>1$. For $a_{3}=1$, an equation for parameters $a_{1}$ and $a_{2}$ is found, that is $a_{1}+a_{1} a_{2}=(y-b)(x=0)$.

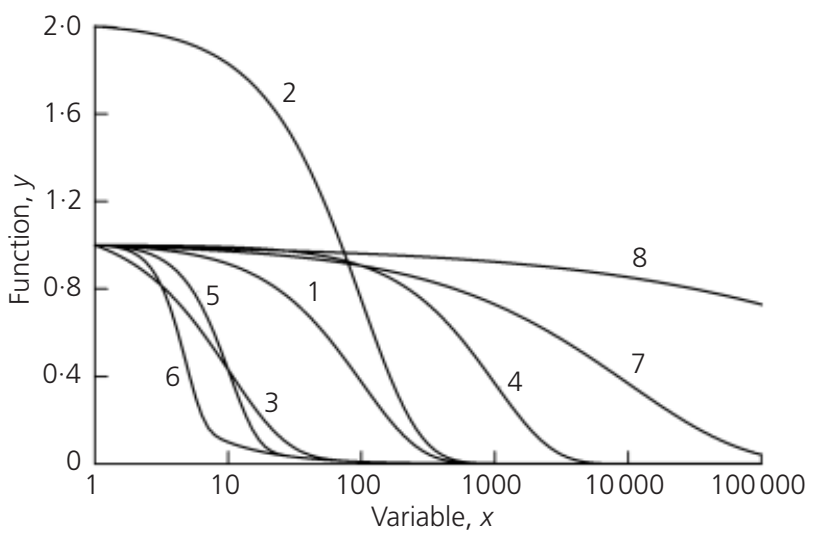

Figure 2. Influence of function parameters 
(d) The value of the first part of the proposed equation monotonically approaches zero as $x$ increases. The rate of the decrease for the absolute value of the first part is determined by parameters $a_{2}$ and $a_{3}$.

The values for function parameters presented in Figure 2 are listed in Table 1. A positive sign of the equation is assumed. $b=0$ is assigned because the physical meaning of the parameter is clear.

Using curve 1 as a base for comparison, it is seen that an increase in the value of $a_{1}$ for curve 2 results in the amplification of the value of function $y$. For curve 3 the value for $a_{2}$ is increased ten times, and for curve 4 the value for $a_{2}$ is decreased ten times. It is seen that the main effect of $a_{2}$ is to shift the S-curve along the $x$ axis. Four curves (curves 5-8) are presented to illustrate the effect of $a_{3}$, two of the curves with $a_{3}>1$, and the other two with $a_{3}<1$. It is clearly shown that the higher the value in $a_{3}$, the sharper the drop in $y$.

Parameter $b$ can be measured directly from the S-shape curve. Parameter $a_{1}$, for $a_{3}>1$, can also be determined directly from the limit value of $y$ as $x$ approaches zero. For $a_{3}=1$, an equation for $a_{1}$ and $a_{2}$ can be obtained from the limit value of $y$ as $x$ approaches zero, which is given in Equation 4. Generally speaking, parameters $a_{1}, a_{2}$ and $a_{3}$ can be determined by fitting the theoretical curve with the known data because every parameter controls a distinct feature of the S-shape relationship.

\section{The application}

In this section, the proposed mathematical function is employed to make simulations of seven types of S-shape relationship observed in engineering and physics, and the capacity of the proposed function is evaluated according to its performance. All the experimental data are obtained from previous publications and they are marked by solid dots in Figure 1 and Figures 3-6.

\subsection{Soil strength and the clay fraction}

Two intrinsic strengths of soils, the critical state strength $\varphi_{\mathrm{cs}}$ and the residual strength $\varphi_{\mathrm{r}}$ are observed to be dependent on the clay fraction of the soil and there exists an S-shape relationship between the soil strengths and clay fraction (e.g. Lupini et al., 1981;

\begin{tabular}{lllll}
\hline Curve & $a_{1}$ & $a_{2}$ & $a_{3}$ & $b$ \\
\hline 1 & 1 & 0.01 & 1 & 0 \\
2 & 2 & 0.01 & 1 & 0 \\
3 & 1 & 0.1 & 1 & 0 \\
4 & 1 & 0.001 & 1 & 0 \\
5 & 1 & 0.01 & 2 & 0 \\
6 & 1 & 0.01 & 3 & 0 \\
7 & 1 & 0.01 & 0.5 & 0 \\
8 & 1 & 0.01 & 0.3 & 0
\end{tabular}

Table 1. Values of function parameters

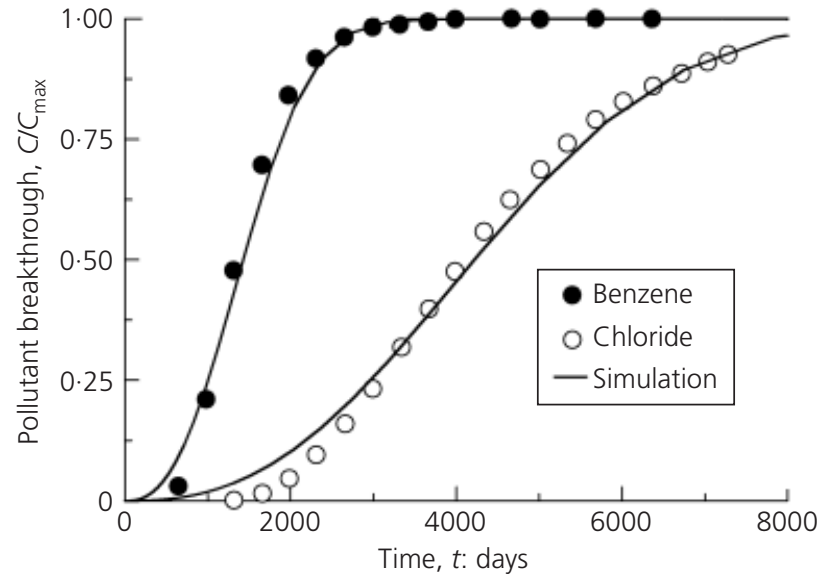

Figure 3. Breakthrough curves of chloride and benzene for sandbentonite line (data after Van Ree et al., 1992)

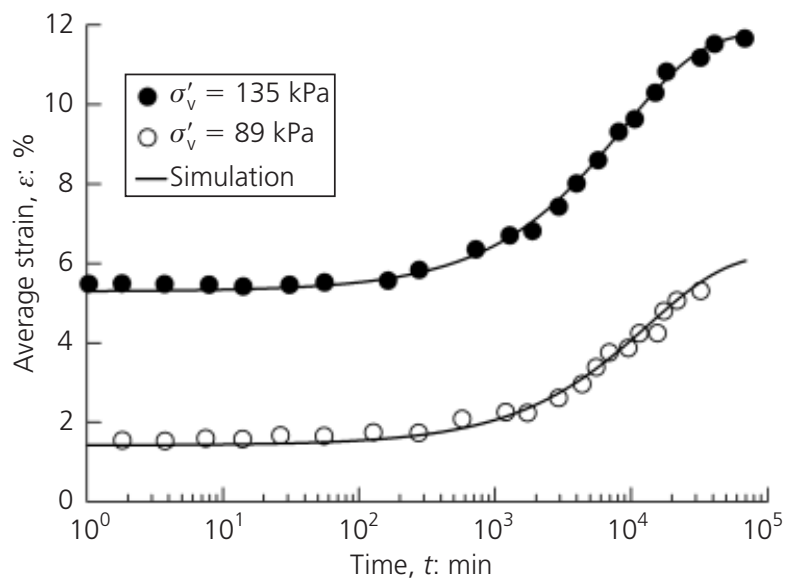

Figure 4. Creep behaviour of Drammen clay (data after Berre and Iversen (1972))

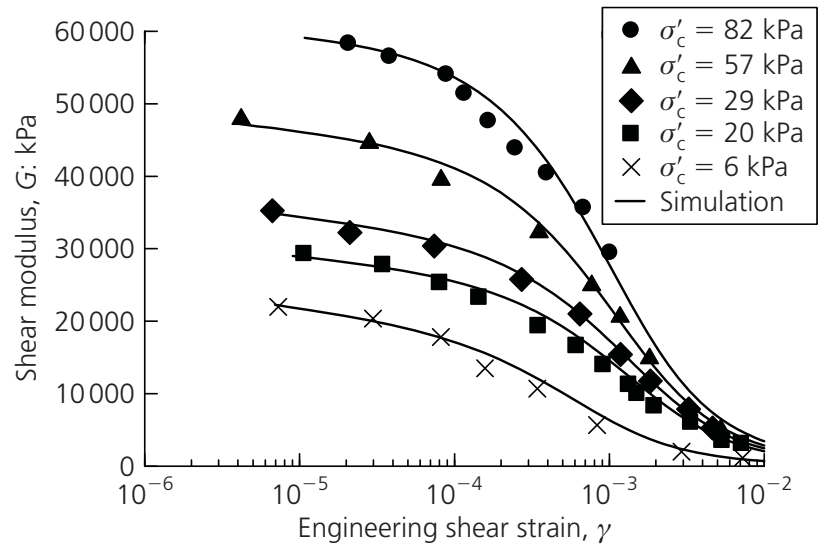

Figure 5. Variation of shear modulus with shear strain (data after Iwasaki et al. (1978)) 


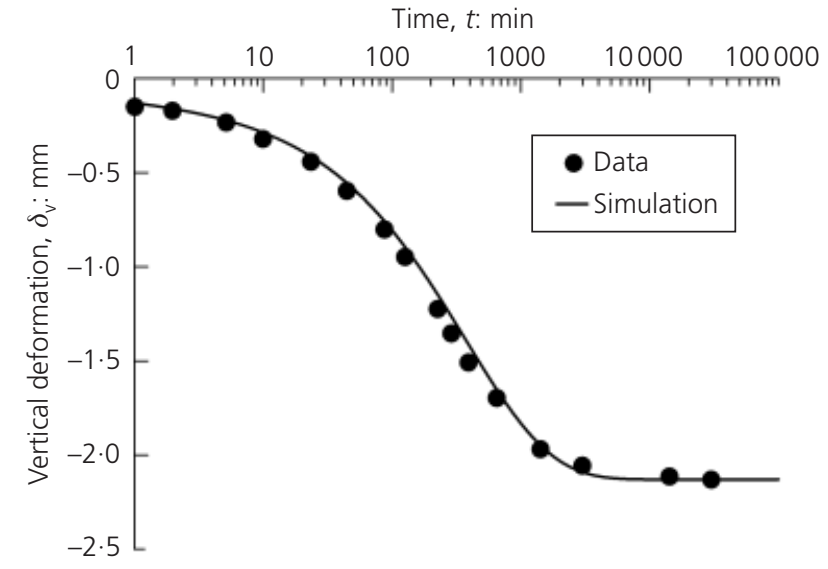

Figure 6. Vertical displacement with time for diatomaceous fill in an oedometer test (data after Day (1997))

Skempton, 1985). The experimental data from Lupini et al. (1981) on the variation of the two intrinsic strengths with clay fraction are quoted here for simulation (Figure 1(a)). The theoretical expressions for the soil strengths found are given below. $\omega_{\mathrm{c}}$ is input as a percentage. The critical state friction angle

$$
\phi_{\mathrm{cs}}=\frac{12}{\omega_{\mathrm{c}}}\left[1+\left(\omega_{\mathrm{c}}-1\right) \mathrm{e}^{-2 \times 10^{-5} \omega_{\mathrm{c}}^{3 \cdot 2}}\right]+20
$$

5. $\left(0 \leqslant \omega_{\mathrm{c}} \leqslant 100\right)$

The residual friction angle

$$
\phi_{\mathrm{r}}=\frac{26}{\omega_{\mathrm{c}}}\left[1+\left(\omega_{\mathrm{c}}-1\right) \mathrm{e}^{-8 \times 10^{-6} \omega_{\mathrm{c}}^{3 \cdot 3}}\right]+5 \cdot 4
$$

6. $\left(0 \leqslant \omega_{\mathrm{c}} \leqslant 100\right)$

The theoretical curves generated by the above two equations are also shown in Figure 1(a) by solid lines.

\subsection{Compression behaviour of soils}

For the compression behaviour of soil under first loading, there exists an S-shape relationship between the voids ratio and the compressive effective stress if the soil is compressed from a very low stress level to the very high stress level, such as from $1 \mathrm{kPa}$ to $10000 \mathrm{kPa}$ (e.g. Pestana and Whittle, 1995; Nagaraj et al., 1990; Horpibulsuk et al. (2007)). The experimental data from Pestana and Whittle (1995) are quoted here for simulation (Figure 1(b)). The voids ratio is denoted by $e$, and the vertical effective stress is denoted by $\sigma_{\mathrm{v}}^{\prime}$. The theoretical expressions found for the three one-dimensional compression tests are given as follows. For the test with initial voids ratio $e=1.03$

$$
\begin{aligned}
& e=\frac{0 \cdot 86}{\sigma_{\mathrm{v}}^{\prime}}\left[1+\left(\sigma_{\mathrm{v}}^{\prime}-1\right) \mathrm{e}^{-2 \cdot 5 \times 10^{-3} \sigma_{\mathrm{v}}^{\prime 0 \cdot 64}}\right]+0 \cdot 18 \\
& \text { 7. }\left(20 \mathrm{kPa} \leqslant \sigma_{\mathrm{v}}^{\prime} \leqslant 100000 \mathrm{kPa}\right)
\end{aligned}
$$

For the test with initial voids ratio $e=0.906$

$$
e=\frac{0 \cdot 74}{\sigma_{\mathrm{v}}^{\prime}}\left[1+\left(\sigma_{\mathrm{v}}^{\prime}-1\right) \mathrm{e}^{-2 \times 10^{-3} \sigma_{\mathrm{v}}^{\prime 0 \cdot 65}}\right]+0 \cdot 18
$$

8. $\left(20 \mathrm{kPa} \leqslant \sigma_{\mathrm{v}}^{\prime} \leqslant 100000 \mathrm{kPa}\right)$

For test with initial voids ratio $e=0.826$

$$
e=\frac{0 \cdot 66}{\sigma_{\mathrm{v}}^{\prime}}\left[1+\left(\sigma_{\mathrm{v}}^{\prime}-1\right) \mathrm{e}^{-1 \cdot 4 \times 10^{-3} \sigma_{\mathrm{v}}^{\prime 0.68}}\right]+0 \cdot 18
$$

9. $\left(20 \mathrm{kPa} \leqslant \sigma_{\mathrm{v}}^{\prime} \leqslant 100000 \mathrm{kPa}\right)$

A comparison between the theoretical curves and the experimental data is shown in Figure 1(b).

\subsection{Pollutant breakthrough curves}

It has been observed that the pollutant breakthrough curves for many materials are S-shaped (e.g. Rowe and Booker, 1985; Van Ree et al., 1992). The experimental data from Van Ree et al. (1992) are shown in Figure 3. The normalised concentration parameter $C / C_{\max }$ increases from zero at $t=0$ to 1 as time $t$ increases. The unit for time is days. The tests include two materials, chloride and benzene. The following theoretical expressions are obtained for describing the breakthrough curves of the two pollutants. For benzene

$$
\frac{C}{C_{\max }}=-\frac{1}{t}\left[1+(t-1) \mathrm{e}^{-9 \times 10^{-9} t^{2 \cdot 5}}\right]+1
$$

10. $(0 \leqslant t<\infty)$

For chloride

$$
\frac{C}{C_{\max }}=-\frac{1}{t}\left[1+(t-1) \mathrm{e}^{-6 \times 10^{-10} t^{2 \cdot 5}}\right]+1
$$

11. $(0 \leqslant t<\infty)$

A comparison between the theoretical curves and the experimental data is shown in Figure 3. Even though the curves slightly divert from the experimental data at very short time period, the overall data are described well. 


\subsection{The S-shape relationship for the creep behaviour of soils}

There are two types of creep behaviour, stable creep and unstable creep. For stable creep behaviour, the relationship between the strain $\varepsilon$ and time $t$ is usually S-shaped (e.g, Berre and Iversen, 1972; Yin and Graham, 1996). The data of one-dimensional compression tests on Drammen clay from Berre and Iversen (1972) are quoted here (Figure 4). Two tests with different vertical effective stresses $\sigma_{\mathrm{v}}^{\prime}$ are considered. The theoretical expressions found for the creep behaviour of the two tests are given as follows. For $\sigma_{\mathrm{v}}^{\prime}=135 \mathrm{kPa}$

$$
\varepsilon=-\frac{6 \cdot 5}{t}\left[1+(t-1) \mathrm{e}^{-1 \cdot 1 \times 10^{-3} t^{0 \cdot 75}}\right]+11 \cdot 8
$$

12. $(0 \cdot 1 \min \leqslant t<\infty)$

For $\sigma_{\mathrm{v}}^{\prime}=89 \mathrm{kPa}$

$$
\varepsilon=-\frac{4 \cdot 8}{t}\left[1+(t-1) \mathrm{e}^{-8 \times 10^{-4} t^{0.75}}\right]+6 \cdot 22
$$

13. $(0 \cdot 1 \min \leqslant t<\infty)$

In the equation, the unit for time is minutes and the strain calculated is a percentage. The theoretical curves are represented in Figure 4 by solid lines.

\subsection{Shear moduli of geomaterials}

It has been widely reported that for geomaterials there is an Sshape relationship between the shear modulus $G$ and the shear strain $\gamma$ (Hight et al., 1992; Iwasaki et al., 1978). The experimental data on the variation of shear modulus with shear strain from Iwasaki et al. (1978) are shown in Figure 5 by points. In the figure, there are six curves for Onahama sand under different confining pressures $\sigma_{\mathrm{c}}^{\prime}$. The units for both stress and modulus are $\mathrm{kPa}$. The values of function parameters identified from the experimental data are listed in Table 2.

The theoretical curves generated by function parameters listed in

\begin{tabular}{lrrrl}
\hline Curve & $a_{1}$ & $a_{2}$ & $a_{3}$ & $b$ \\
\hline$\sigma_{\mathrm{c}}^{\prime}=82 \mathrm{kPa}$ & 34.3 & 1550 & 0.99 & 0 \\
$\sigma_{\mathrm{c}}^{\prime}=57 \mathrm{kPa}$ & 28.4 & 1300 & 0.98 & 0 \\
$\sigma_{\mathrm{c}}^{\prime}=29 \mathrm{kPa}$ & 24.5 & 1000 & 0.97 & 0 \\
$\sigma_{\mathrm{c}}^{\prime}=20 \mathrm{kPa}$ & 20.6 & 1000 & 0.97 & 0 \\
$\sigma_{\mathrm{c}}^{\prime}=10 \mathrm{kPa}$ & 10.3 & 1400 & 0.95 & 0 \\
$\sigma_{\mathrm{c}}^{\prime}=5 \mathrm{kPa}$ & 6.9 & 1800 & 0.95 & 0
\end{tabular}

Table 2. Values of function parameters
Table 2 are shown in Figure 5 by solid lines. The parameters $a_{1}$, $a_{2}$ and $a_{3}$ are the best fitting for the range of strains considered.

\subsection{Consolidation and creep behaviour of soils}

In an oedometer test, the vertical displacement, denoted by $\delta_{\mathrm{v}}$, is made up of two parts, namely the part contributed by the increment in the effective stresses and the part contributed by creep effect. The former is usually defined as primary consolidation, and the latter is defined as secondary consolidation. The total settlement plotted against time for a soil specimen in an oedometer test is usually S-shaped (Day, 1997; Ladd et al., 1977). The experimental data from an oedometer test on diatomaceous fill reported by Day (1997) are simulated (Figure 6). The total vertical stress is maintained at $50 \mathrm{kPa}$ for the test. The theoretical expression found is

$$
\delta_{\mathrm{v}}=\frac{2}{t}\left[1+(t-1) \mathrm{e}^{-0 \cdot 02 t^{0 \cdot 66}}\right]-2 \cdot 13
$$

14. $(0 \cdot 1 \min \leqslant t<\infty)$

The vertical settlement $\delta_{\mathrm{v}}$ is defined as negative and its unit is millimetres. The unit for time $t$ is minutes. A comparison between the theoretical curves and the experimental data is shown in Figure 6.

\subsection{Consolidation deflection of circular rafts}

The consolidation deflection of a raft on a deep layer of soil plotted against time is an S-shape relationship (Booker and Small, 1984; Gibson et al., 1970). The time deflection at the centre of a circular raft with various flexibility reported by Booker and Small (1984) is shown in Figure 1(c). In the figure, $\delta_{\mathrm{c}}$ is the deflection at the centre of a circular raft normalised by the uniform loading acting on the raft; $T^{\prime}$ is a time factor and is defined as $T^{\prime}=c t / a^{2} \times 1000$, where $c$ is the coefficient of onedimensional consolidation, $t$ is time and its unit is minutes and $a$ is the radius of the circular raft.

The theoretical expressions found are given as follows

For $K=0$

$$
\begin{aligned}
\delta_{\mathrm{c}} & =-\frac{0 \cdot 9}{T^{\prime}}\left[1+\left(T^{\prime}-1\right) \mathrm{e}^{-0 \cdot 05 \sqrt{T^{\prime}}}\right]+1 \cdot 93 \\
\text { 15. } \quad\left(1 \leqslant T^{\prime}<\infty\right) &
\end{aligned}
$$

For $K=1$

$$
\delta_{\mathrm{c}}=-\frac{0 \cdot 7}{T^{\prime}}\left[1+\left(T^{\prime}-1\right) \mathrm{e}^{-0 \cdot 042 \sqrt{T^{\prime}}}\right]+1 \cdot 62
$$

16. $\left(1 \leqslant T^{\prime}<\infty\right)$ 
For $K=\infty$

$$
\delta_{\mathrm{c}}=-\frac{0 \cdot 62}{T^{\prime}}\left[1+\left(T^{\prime}-1\right) \mathrm{e}^{-0 \cdot 042 \sqrt{T^{\prime}}}\right]+1.45
$$

17. $\left(1 \leqslant T^{\prime}<\infty\right)$

The curves generated by the above three expressions are also shown in Figure 1(c) by solid lines.

\section{Discussion}

Seven types of S-shape relationship encountered in geotechnical engineering practice are considered. Five of them describe material properties which are independent of the material size. They are

(a) peak shear strength of clayey soil

(b) compression behaviour of soil

(c) breakthrough curves for pollutants

(d) creep behaviour of soils

(e) shear moduli of geomaterials.

The other two describe the response of a system and the quantitative features of the responses are associated with a particular system only. They are

(a) consolidation and creep behaviour of soil in an oedometer test

(b) deflection of a circular raft with time.

Comparing the simulations and the experimental data, it is seen that all those S-shape relationships in both normal $x$ and $y$ scale and the semi-logarithmic $x$ and $y$ scale have been successfully represented by the proposed new mathematical function.

The following features are observed in simulating S-shape relationships of materials.

(a) Situations with both $a_{3} \geqslant 1$ and $0<a_{3}<1$ are encountered in engineering practice.

(b) For situations with $a_{3} \geqslant 1$, the simulation by way of the proposed function is usually valid for the total valid range for $x$ defined by the practical problem. However, for a situation with $0<a_{3}<1$, the simulation by way of the proposed function is usually valid only for the range simulated. To illustrate the point, the valid range for Equations 15 through 17 is $1 \leqslant T^{\prime}<\infty$, which is the range simulated. However, the valid range of this practical problem is $0 \leqslant T^{\prime}<\infty$. It is also observed that data obtained by extrapolation for the former case are more reliable than for the latter case.

(c) For situations with $a_{3} \geqslant 1$ two of the parameters are determined by fitting. The determination of the function parameters is found to be simple and direct according to the features that each parameter control. It appears that a unique set of parameters may be determined by fitting. For situations with $0<a_{3}<1$ all the three parameters are determined by fitting, and the technique of trial and error may be required. Compared with the former situation, the values of function parameters are more sensitive to the range of variable $x$ for simulation.

\section{Conclusion}

In engineering and physics, it has often been observed that some material characteristics and system responses exhibit an S-shape relationship. A new mathematical function is proposed for describing this relationship in both normal $x$ and $y$ scale and the semi-logarithmic $x$ and $y$ scale. The proposed function has been used to simulate the S-shape relationship of seven types of engineering phenomena, and it has been demonstrated that the proposed mathematical function describes all the events satisfactorily and can be used for characterising properties of materials or systems and thus is valuable for further numerical analysis.

\section{Acknowledgements}

The authors would like to express their thanks to Professors H. G. Poulos, J. P. Carter and B. Indraratna for the useful discussions and assistance in preparing this paper. The authors would also like to acknowledge their appreciation of the financial support from the Suranaree University of Technology.

\section{REFERENCES}

Berre T and Iversen K (1972) Oedometer tests with different specimen heights on a clay exhibiting large secondary compression. Géotechnique 22(1): 53-70.

Booker JR and Small JC (1984) The time-deflection behaviour of a circular raft of finite flexibility on a deep clay layer. International Journal for Numerical Analytical Methods in Geomechanics 8(4): 343-357.

Burland JB (1990) On the compressibility and shear strength of natural soils. Géotechnique 40(3): 329-378.

Butterfield R and Baligh F (1996) A new evaluation of loading cycles in an oedometer. Géotechnique 46(3): 547-553.

Day RW (1997) Discussion on 'engineering properties of diatomaceous fill' closure by Day. Journal of Geotechnical and Geoenvironmental Engineering, ASCE 123(6): 589-592.

Gibson RE, Schiffman RL and Pu SL (1970) Plane strain and axially symmetrical consolidation of a clay on a smooth impervious base. Quarterly Journal of Mechanics and Applied Mathematics 23(4): 505-519.

Hight DW, Bond AJ and Legge JD (1992) Characterisation of the Bothkennar clay: an overview. Géotechnique 42(2): 303-347.

Horpibulsuk S, Liu MD, Liyanapathirana DS and Suebsuk J (2010) Behavior of cemented clay simulated via the theoretical framework of the structured Cam Clay model. Computers and Geotechnics 37(1-2): 1-9.

Horpibulsuk S, Shibuya S, Frenkajorn K and Katkan W (2007) Assessment of engineering properties of Bangkok clay. Canadian Geotechnical Journal 44(2): 173-187.

Khalili N, Habte MA and Valliappan S (2005) A bounding surface 
plasticity model for cyclic loading of granular soils. International Journal for Numerical Methods in Engineering 63(14): 1939-1960.

Iwasaki T, Tatsuoka F and Takagi Y (1978) Shear moduli of sands under cyclic torsional shear tests. Soils and Foundations 18(1): $39-56$.

Ladd CC, Foott R, Ishihara K, Schlosser F and Poulos HG (1977) Stress-deformation and strength characteristics. Proceedings of the 9th International Conference on Soil Mechanics and Foundation Engineering, Tokyo, Japan, vol. 2, pp. 421-494.

Liu MD and Carter JP (2003) The volumetric deformation of natural clays. International Journal of Geomechanics, ASCE 3(3/4): 236-252.

Lupini JF, Skinner AE and Vaughan PR (1981) The drained residual strength of cohesive soils. Géotechnique 31(2): 181-213.

Nagaraj TS, Srinivasa Murthy BR, Vatsala A and Joshi RC (1990) Analysis of compressibility of sensitive clays. Journal of Geotechnical Engineering, ASCE 116(GT1): 105-118.

Pestana JM and Whittle AJ (1995) Compression model for cohesionless soils. Géotechnique 45(4): 621-631.
Rowe RK and Booker JR (1985) 1-D pollutant migration in soils of finite depth. Journal of Geotechnical Engineering, ASCE 111(4): 479-499.

Skempton AW (1985) Residual strength of clays in landslides, folded strata and the laboratory. Géotechnique 35(1): 1-18.

Suebsuk J, Horpibulsuk S and Liu MD (2010) Modified structured Cam Clay: A constitutive model for destructured, naturally structured and artificially structured clays. Computers and Geotechnics 37(7-8): 956-968.

Suebsuk J, Horpibulsuk S and Liu MD (2011) A critical state model for overconsolidated structural clays. Computers and Geotechnics 38(5): 648-658.

Terzaghi K and Peck RB (1948) Soil Mechanics in Engineering Practice. Wiley, New York, NY, USA.

Van Ree CCDF, Weststrate FA, Meskers CG and Bremmer CN (1992) Design aspects and permeability testing of natural clay and sand-bentonite liners. Géotechnique 42(1): 49-56.

Yin JH and Graham J (1996) Elastic visco-plastic modelling of one-dimensional consolidation. Géotechnique 46(3): 515527.

\section{WHAT DO YOU THINK?}

To discuss this paper, please email up to 500 words to the editor at journals@ice.org.uk. Your contribution will be forwarded to the author(s) for a reply and, if considered appropriate by the editorial panel, will be published as a discussion in a future issue of the journal.

Proceedings journals rely entirely on contributions sent in by civil engineering professionals, academics and students. Papers should be 2000-5000 words long (briefing papers should be 1000-2000 words long), with adequate illustrations and references. You can submit your paper online via www.icevirtuallibrary.com/content/journals, where you will also find detailed author guidelines. 